\title{
Biodegradation Studies in Vitro of Novel Poly(adipic anhydride-co-mannitol)-N-maleoyl Chitosan Networks
}

\author{
Mahir A. Jalal" \\ Hadi S. Al-Lami*** \\ *Department of Polymer Technology, Polymer Research Center, University of \\ Basrah, Iraq \\ **Department of Chemistry, College of Science, University of Basrah, Iraq \\ E-mail: hadisalman54@yahoo.com
}

Received 11/10/2015

Accepted 20/12/2015

(1) $9 \Theta$

EY No ND This work is licensed under a Creative Commons Attribution-NonCommercial-

NoDerivatives 4.0 International Licens

\begin{abstract}
:
In this work, novel copolymers of poly(adipic anhydride-co-mannitol) were synthesized by melting condensation polymerization of poly(adipic anhydride) with five percentages of mannitol sugar, 1 to $5 \mathrm{Wt} . \%$. These copolymers were purified and then, characterized by FT-IR, which was proved that the cross-linking reaction was caused by nucleophilic attack of mannitol hydroxyl group to acidic anhydride groups of poly(adipic anhydride) backbone and new ester groups were formed and appeared. Also, modified organic-soluble chitosan, N-maleoyl-chitosan, were synthesized by grafting reaction of chitosan with maleic anhydride in DMF as solvent, and it was also purified and characterized by FT-IR. Biodegradation in vitro of the IPNs of poly(adipic anhydride-co-mannitol)-N-maleoyl chitosan networks were evaluated by hydrolytic degradation studies at three different media (PBS, SIF and SGF) for 18 weeks with $92 \%$ as maximum degradation and it was found that minimum weight loss of IPNs was noticeably shown in SIF. In addition, hydrolytic degradation percent was decreased with increasing mannitol proportions.
\end{abstract}

Key words: melt condensation, poly(adipic anhydride), mannitol, poly(adipic anhydride-co-mannitol), biodegradable polymer, in vitro degradation .

\section{Introduction:}

Synthetic biodegradable polymers have been extensively investigated as useful biomaterials for bone and cartilage repairing, controlled drug delivery systems, and tissue engineering applications [1]. Many types of synthetic polymers have been found to be biodegradable materials, including polyesters, polyanhydrides, poly(ortho esters), poly(phosphazenes), etc. [2].
Poly(aliphatic esters), such as poly(D,Llactide) (PDLLA), poly(l-lactide) (PLLA), poly( $\varepsilon$-caprolactone) (PCL), poly(glycolide) (PGA) homopolymers as well as their random or block copolymers, are the most widely used biodegradable polymers in clinics as medical devices or drug delivery carriers due to their biocompatibility, biodegradability, high-purity, and the 
ease to be produced in a large-scale [3]. Also, polyanhydirde is one of few classes of synthetic biodegradable polymers that have received great attention through the past decades. They have been widely used as antibiotics [4], anesthetics [5], controlled delivery of a number of drugs containing chemotherapeutics [6], and polypeptides [7].

Hui and et al [8] synthesized poly (sebacic anhydride-co-caprolactone), poly(anhydride-ester) multi-block copolymer, and showed different crystallization kinetics with two stages degradation behaviour; rapid hydrolysis of anhydride linkage groups, and slower hydrolysis of remaining ester groups. Also, bioactive-based poly(anhydrideesters) and blends are one of therapeutic biodegradable that hydrolytically degrade into bioactive components which conjugated as pendant groups or directly incorporated into the polymer backbone [9]. Schmeltzer and et al [10] synthesized poly(anhydride esters) that were composed of several salicylate derivatives, including halogenated salicylates, aminosalicylates, salicylsalicylic acid, and thiolsalicylic acid, and studied in vitro degradation lag times from 1 to 3 days. Recently, a number of papers have reported the combinatorial synthesis of polymers through enzyme-assisted polymerization, microwave polymerization, or by judicious choice of polymerization reaction chemistries [11-14].

In this work, we are interested in the synthesis poly (anhydride-ester) formulating of poly(adipic anhydrideco-manitol) by melting condensation polymerization and study their in vitro degradation behaviour as IPNs with chitosan derivative which it might be suitable for different medical applications.

\section{Materials and Methods Materials}

Local shrimp shells were used as a main source of Chitin; they were well isolated from shrimps, washed and dried at room temperature. Adipic acid and acetic anhydride were supplied by BDH and Sigma-Aldrich respectively. Mannitol sugar (Sigma-Aldrich) used as crosslinking agent for preparation adipic anhydride polymer. It was purified and crystallized by dissolving in ethanol, filtered, precipitated in diethyl ether and dried under vacuum at room temperature. Solvents, including methylene chloride, petroleum ether, dimethylformamide and diethyl ether purchased from GCC and dried perfectly by sodium wire, then freshly distilled prior to use.

\section{Methods}

\section{Preparation of Chitosan}

Shrimp shells (100g) were dried at $100^{\circ} \mathrm{C}$ for 12 hours and ground to powder, then $1000 \mathrm{ml}$ of $(5 \%)$ hydrochloric acid solution was added to the powder and stirred vigorously by mechanical stirrer for 24 hours at room temperature to remove minerals and their salts. The residual powder was filtered and washed twice with distilled water to remove residual hydrochloric acid. Deproteinization were achieved by mixing $1000 \mathrm{ml}$ of (10\%) sodium hydroxide solution with the powder and stirred mechanically for 3 hours at $90^{\circ} \mathrm{C}$. The mixture was cooled down to room temperature, filtered and washed with water to obtain chitin powder. Next, $20 \mathrm{~g}$ of chitin and $250 \mathrm{ml}$ of $(50 \%)$ potassium hydroxide solution were charged in Three-neck round bottom flask, which was fitted with a stirrer, condenser and thermometer. The mixture was heated to $90^{\circ} \mathrm{C}$ for 6 hours. Finally, residual was washed by water and dried [15]. It was characterized by FT-IR, the yield was $78 \%$. 
The $2^{\text {nd }}$ National Conference of Chemistry

\section{Synthesis of N-maleoyl Chitosan (NMCS)}

Modified organic-soluble chitosan were prepared by dissolving $2 \mathrm{~g}$ Chitosan and $6 \mathrm{~g}$ maleic anhydride into100 $\mathrm{ml}$ of dimethylformamide (DMF). The mixture was stirred at $130^{\circ} \mathrm{C}$ for 3 hours under nitrogen atmosphere. The reacted solution was cooled to room temperature and poured into an ice water to precipitate the product. The product was collected by filtration, washed with diethyl ether for three times, then dried in vacuum at $40^{\circ} \mathrm{C}$ [16]. The greyish-white powder of N-maleoyl-chitosan (NMCS) was obtained with yield of $46 \%$. It was characterized by FT-IR spectroscopy.

\section{Preparation of Poly(adipic anhydride)}

An amount $24 \mathrm{~g}$ of adipic acid and $248 \mathrm{~g}$ of acetic anhydride were charged into a three-neck round bottom flask fitted with a condenser and thermometer. The reaction was processed under dry nitrogen gas at reflux temperature for 20 minutes. Then, rotary evaporator was used to remove unreacted acetic anhydride and the resulted acetic acid. The crude prepolymer was recrystallized from dry toluene. Subsequently, the crystals were immersed in dry solvent of 1:1 dry petroleum ether and diethyl ether to extract residual acetic anhydride and toluene. The poly(adipic anhydride) was dried under vacuum for 48 hours [17], and the results are white crystals with yield $81 \%$, which was also characterized by FT-IR.

\section{Preparation of Poly(adipic anhydride-co-mannitol)}

Two grams of poly(adipic anhydride) and (1, 2, 3, 4, and 5\% wt.) of mannitol were placed in the vacuum glass tube $(2 * 15 \mathrm{~cm})$. The cross-linking reaction was carried out as meltcondensation polymerization at $180^{\circ} \mathrm{C}$ by bath oil under high vacuum condition, about 50-20 $\mathrm{Pa}$, and magnetic stirrer for 120 minutes during the polymerization process, a strong nitrogen sweep with vigorous agitation of the melt was applied for $30 \mathrm{~S}$ every 15 minutes. The crude polymer was purified by dissolving into dry methylene chloride and then precipitated by filtered into stirred dry petroleum ether to extract adipic acid. The precipitated was filtered off, washed with petroleum ether and dried at $40^{\circ} \mathrm{C}$ under vacuum for 48 hours [17] to give $79 \%$ yield. The polymer was characterized by FT-IR.

\section{Preparation of Poly(adipic anhydride-co-mannitol)-N-maleoyl chitosan IPN's}

$0.5 \mathrm{~g}$ of poly(adipic anhydride-comannitol) and $0.5 \mathrm{~g}$ of modified chitosan were dissolved into $10 \mathrm{ml}$ of dry methylene chloride. The blend was precipitated by dry petroleum, washed with dry diethyl ether and dried for 48 hours at $40^{\circ} \mathrm{C}$. Table (1) shows the prepared specimen codes according to mannitol wt.\%.

Table (1) Prepared samples codes

\begin{tabular}{|c|c|}
\hline $\begin{array}{c}\text { poly(adipic anhydride- } \\
\text { co-mannitol)-chitosan } \\
\text { network code }\end{array}$ & $\begin{array}{c}\text { wt.\% of } \\
\text { Mannitol }\end{array}$ \\
\hline N1 & $1 \%$ \\
\hline N2 & $2 \%$ \\
\hline N3 & $3 \%$ \\
\hline N4 & $4 \%$ \\
\hline N5 & $5 \%$ \\
\hline
\end{tabular}

\section{In vitro Biodegradation}

\section{Measurement}

The biodegradability of blend polymers (N1-N5) was studied by weight loss method. $0.3 \mathrm{~g}$ of sample and 10-ton pressure were needed to prepare disks with $1 \mathrm{~cm}$ diameter and $3 \mathrm{~mm}$ height. Disks were immersed in $30 \mathrm{ml}$ of three different mediums; simulated gastric fluid ( $\mathrm{SGF}, \mathrm{pH}=1.2$ ), simulated intestinal fluid (SIF, $\mathrm{pH}=8.2$ ) and Phosphate buffer solution (PBS, $\mathrm{pH}=7.4$ ) at room temperature. 
Degradation or weight loss of samples can be determine by the fraction of initial disk weight $\left(\mathrm{W}_{\mathrm{o}}\right)$ and disk weight after a particular period $\left(\mathrm{W}_{\mathrm{t}}\right)$, as mention in equation $1[18,19]$ :

$$
\text { Weight loss }(\%)=\frac{W \circ-W t}{W t} * 100
$$

\section{Results and Discussion}

Due to the limited solubility of chitosan in organic solvents, chemical modification affords a wide range of chitosan derivatives. N-maleoyl chitosan is organic-soluble derivative, which was achieved by grafting of chitosan $\mathrm{NH}_{2}$ with carboxylic acid as shown in Scheme 1. While, preparation of poly(adipic anhydride-co-mannitol) is a crosslinking process that fall into partial crosslinking achieved by nucleophilic attack of the mannitol hydroxyl groups to the linkages along the acid anhydride groups of PAA backbone chains at specific conditions, the anhydride linkages will form cleavages by esterification mechanism, as shown in Scheme 2.
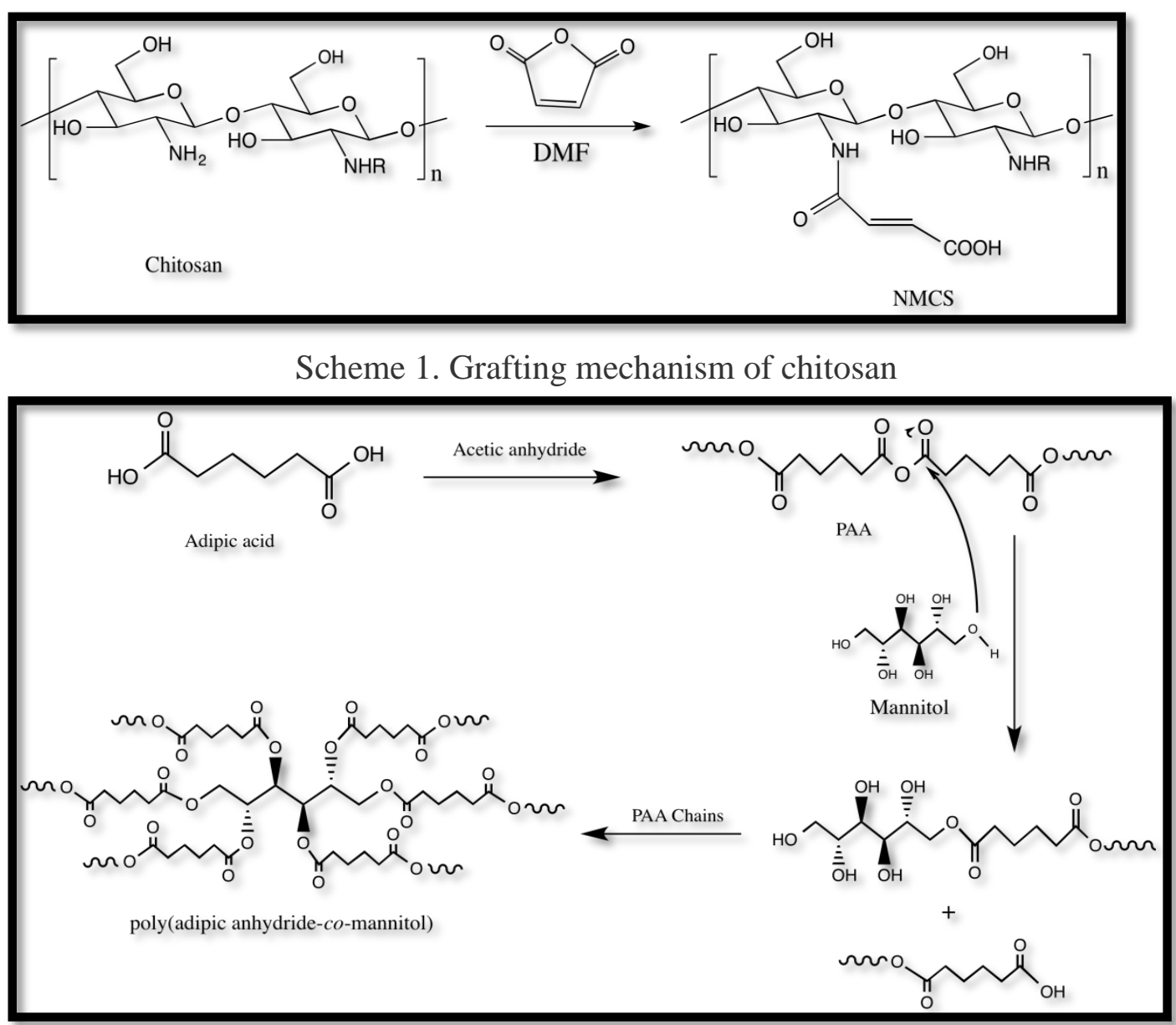

Scheme 2. Crosslinking mechanism of poly(adipic anhydride-co-mannitol).

\section{FT-IR Analysis}

The reactant materials and products are characterized by JASCO FTIR 4200 instrument and the results of those analyses are presented in Figures 1-7. The FTIR spectrum of chitosan, as exhibited in Figure 1, shows a broad peak between 3600$3100 \mathrm{~cm}^{-1}$ which assigned for stretching of hydroxyl groups and two peaks at $3300 \mathrm{~cm}^{-1}$ and $3108 \mathrm{~cm}^{-1}$ related to stretching of $\mathrm{NH}_{2}$ groups [20]. Other two peaks at $2931 \mathrm{~cm}^{-1}$ and $2879 \mathrm{~cm}^{-1}$ represent the symmetric and 
The $2^{\text {nd }}$ National Conference of Chemistry

asymmetric stretching of aliphatic $\mathrm{C}-\mathrm{H}$ bond for methylene groups respectively. The stretching of the $\mathrm{C}-\mathrm{O}$ group appears as a sharp peak at 1072 $\mathrm{cm}^{-1}$.

Figure 2 shows the FT-IR spectrum of N-maleoyl chitosan which indicates the appearance of three groups: ester carbonyl group as strong peak at $1718 \mathrm{~cm}^{-1}$, a sharp peak at 1627 $\mathrm{cm}^{-1}$ for $\mathrm{C}=\mathrm{C}$ group stretching, and strong peak at $1690 \mathrm{~cm}^{-1}$ for carboxylic acid carbonyl groups [20]. In addition, the disappearance of the two peaks assigned for $\mathrm{NH}_{2}$ group at $3300 \mathrm{~cm}^{-1}$ and $3108 \mathrm{~cm}^{-1}$ confirm the ring opening of maleic anhydride and grafted with free $\mathrm{N}$-substituted of chitosan.

On the other side, poly(adipic anhydride) is also characterized by FT-
IR and a spectrum obtained is shown in Figure 3. It exhibits two strong and sharp peaks at $1831 \mathrm{~cm}^{-1}$ and $1742 \mathrm{~cm}^{-1}$ assigned for stretching carbonyl of acidic anhydride groups along polymer backbone chains. The $\mathrm{C}-\mathrm{O}$ stretches for the same group also appear as a strong peak at $1021 \mathrm{~cm}^{-1}$. The carboxylic acid at the end of polymer chains showed a weak peak at $1702 \mathrm{~cm}^{-1}$ [20]. Figures 47 are presenting spectra of poly(adipic anhydride-co-mannitol) with different mannitol proportions. In comparison with poly(adipic anhydride), there is a peak strongly increased with increasing mannitol preparations. This peak at $1730 \mathrm{~cm}^{-1}$ related to carbonyl ester groups formed by crosslinking reaction of melt-condensation polymerization.

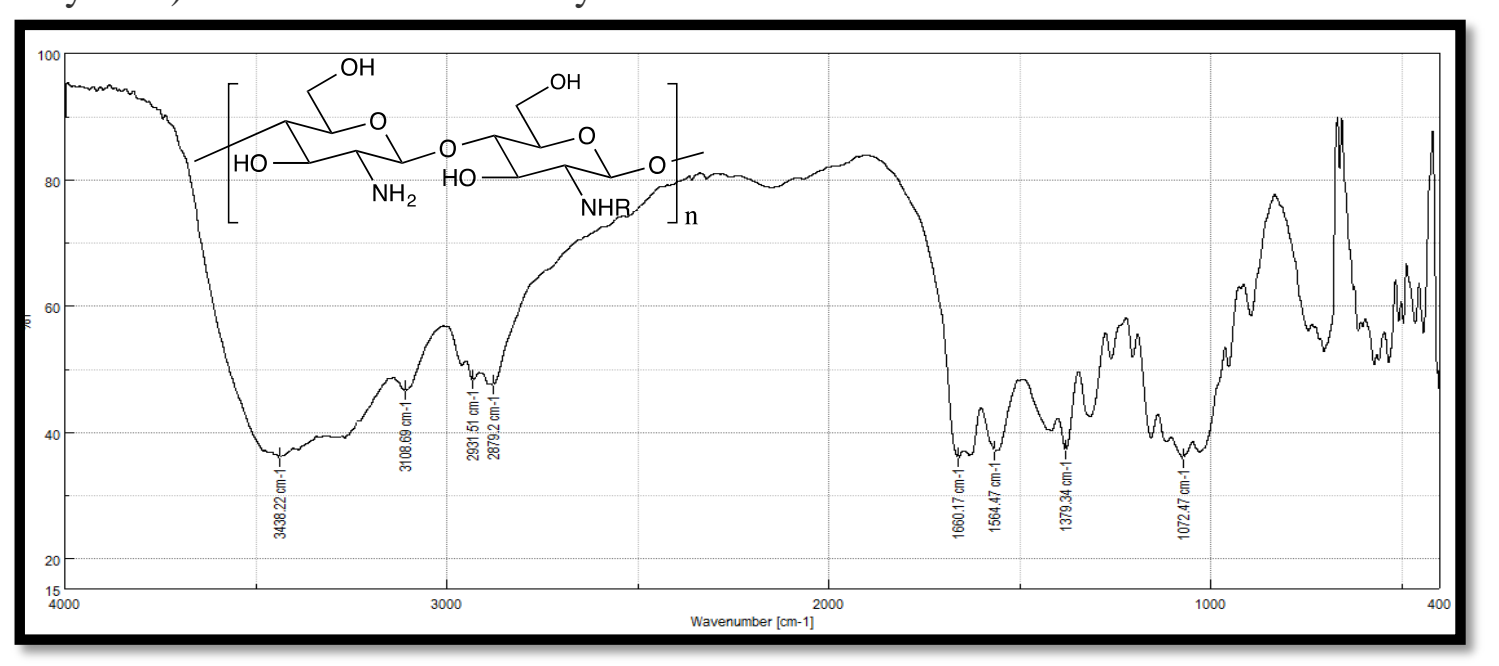

Figure 1. FT-IR spectrum for chitosan

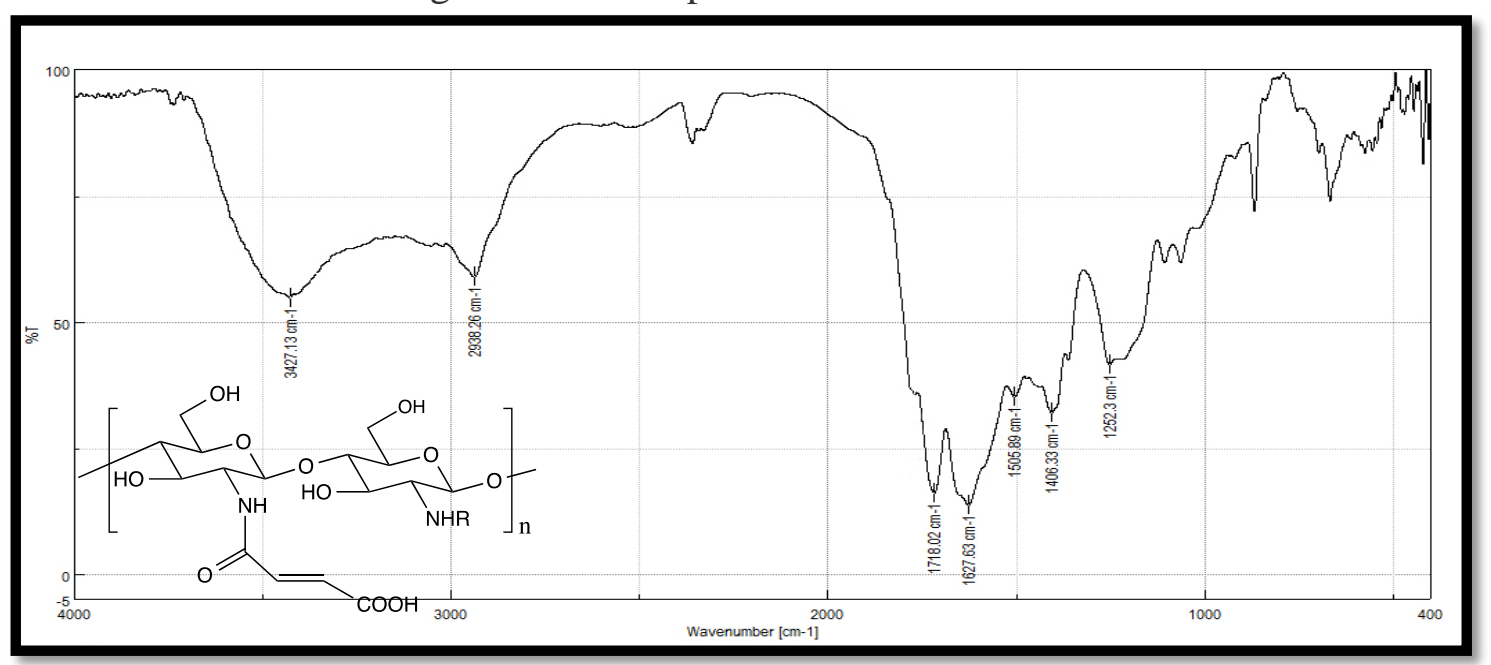

Figure 2. FT-IR spectrum for N-maleoyl chitosan 


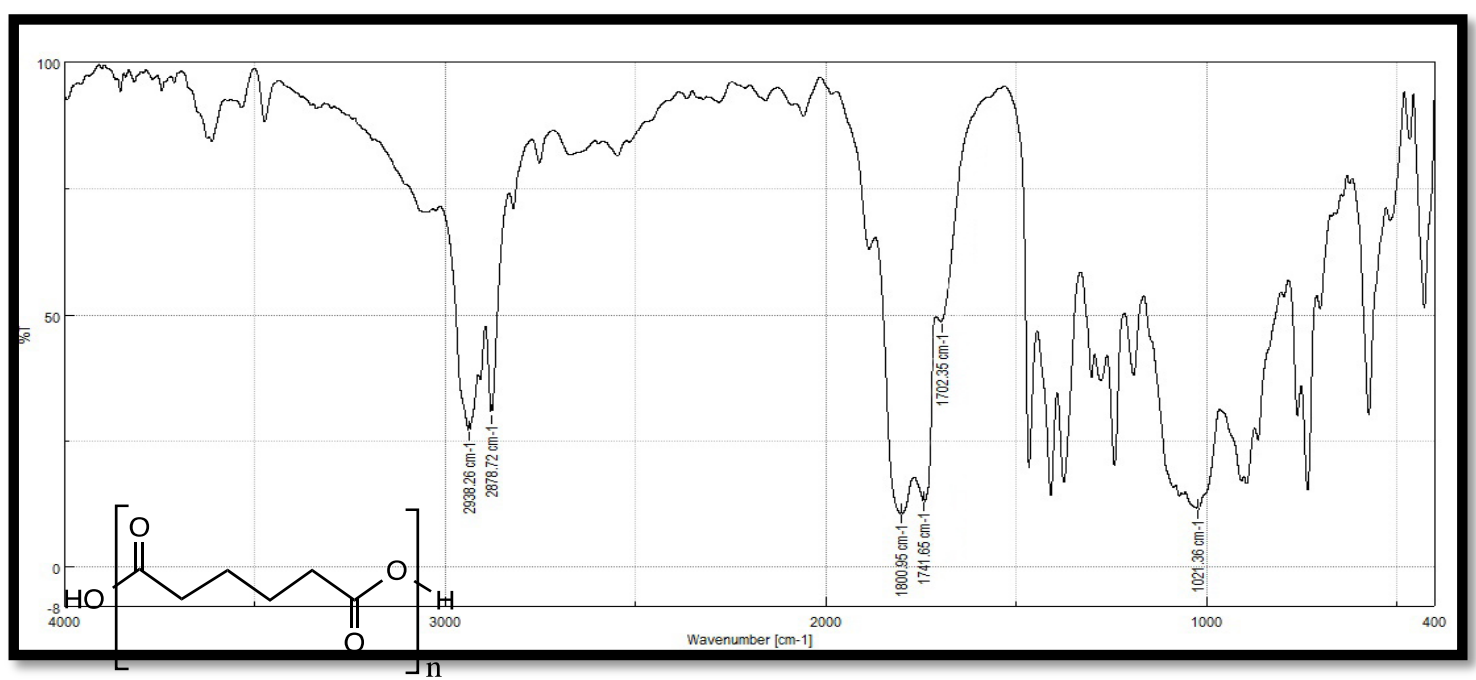

Figure 3. FT-IR spectrum for PAA

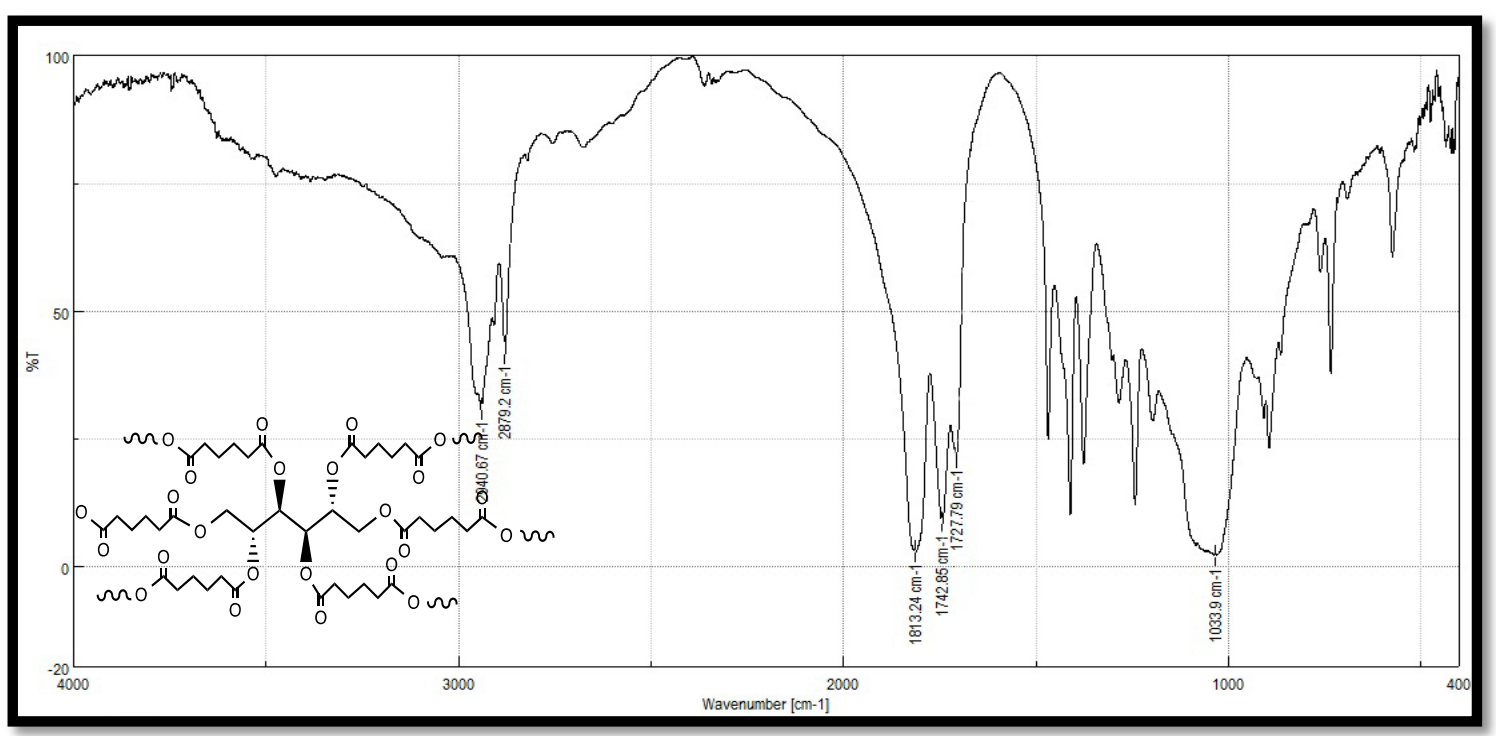

Figure 4. FT-IR spectrum for N2

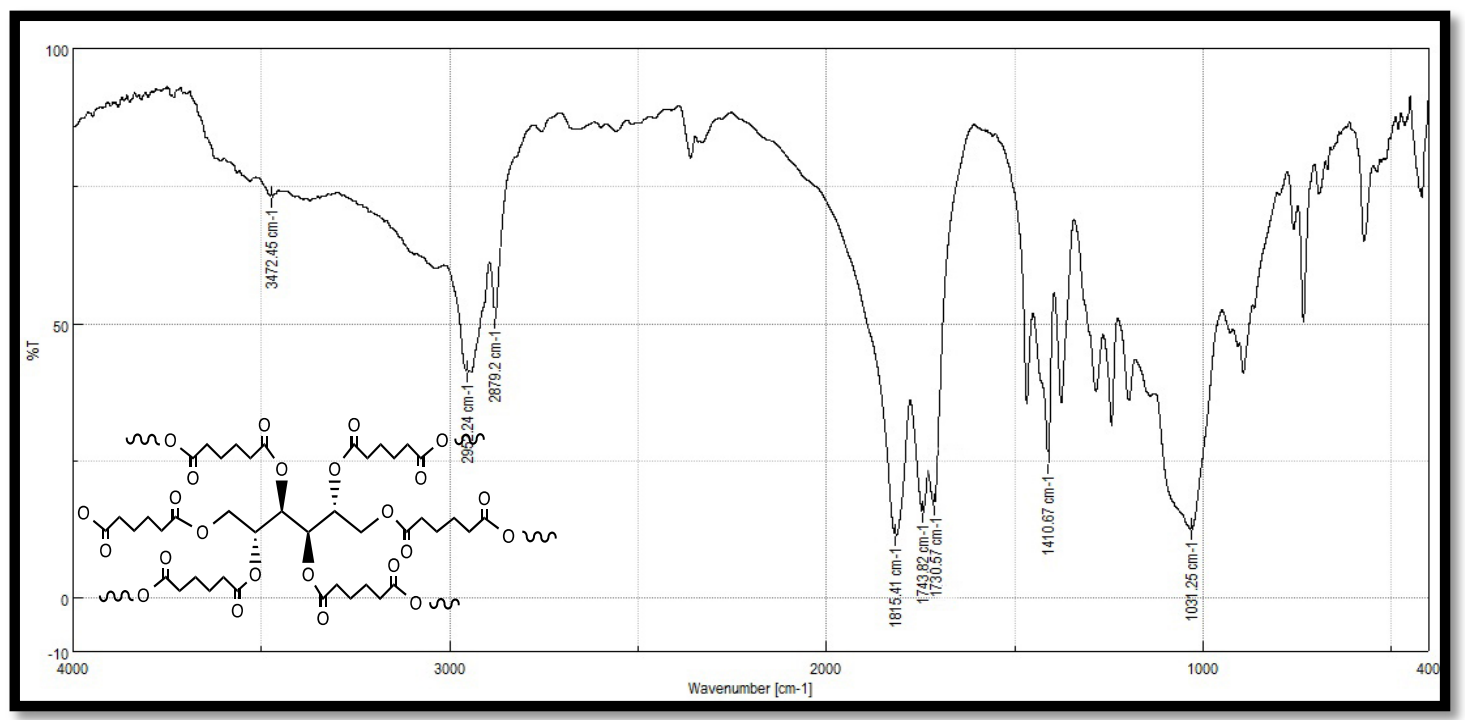

Figure 5. FT-IR spectrum for N3 


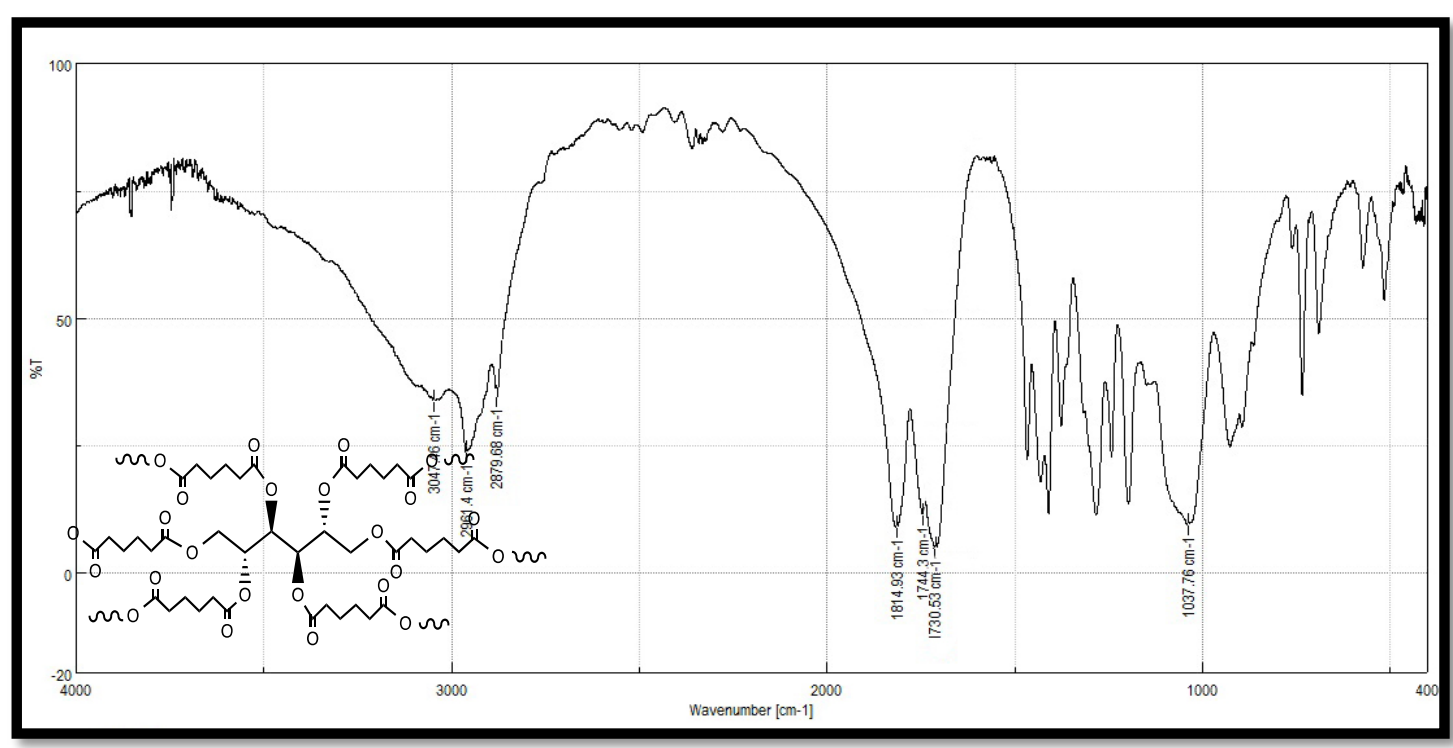

Figure 6. FT-IR spectrum for N4

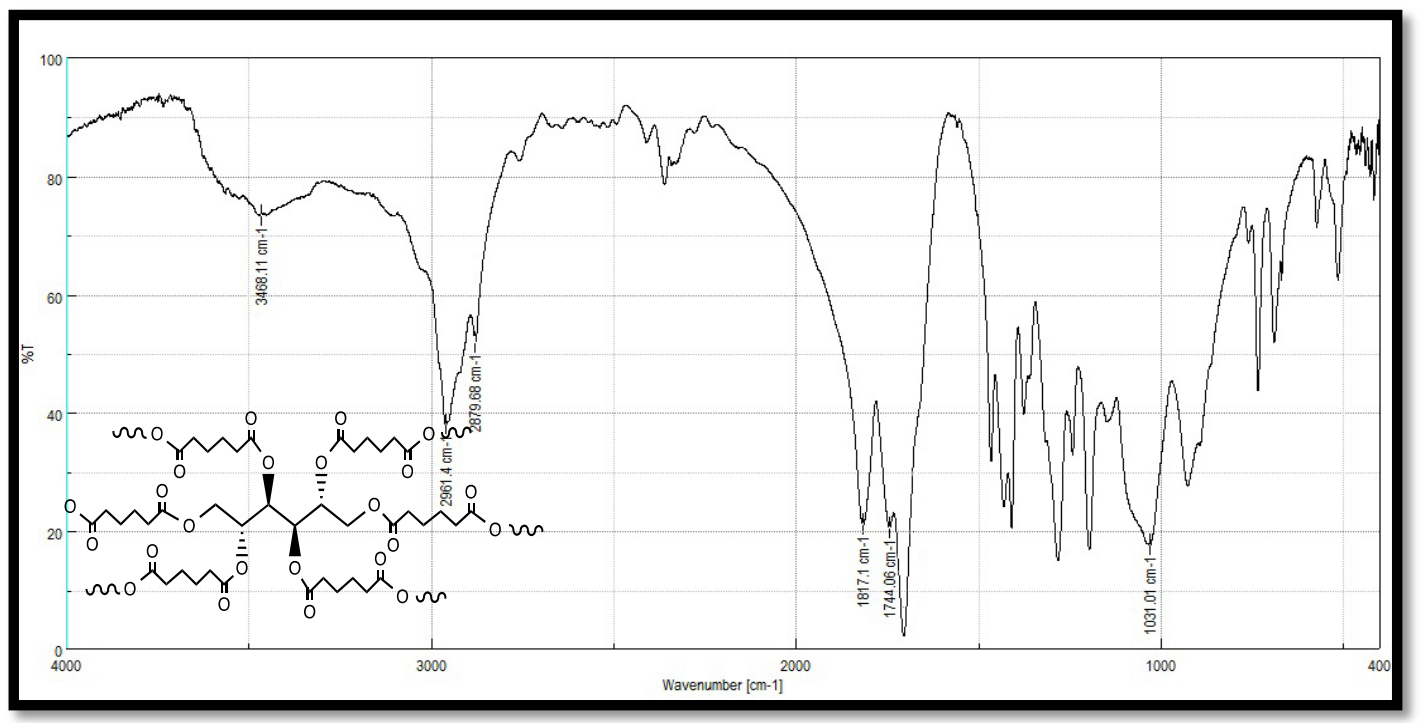

Figure 7. FT-IR spectrum for N5

\section{In vitro Biodegradation Assessments}

Weight loss measurement of polymer matrix is a common method that is currently used by many researchers to evaluate in vitro polymer degradation. By immersing certain amount of polymer in buffer solution, penetration of the solution takes place through polymer matrix, i.e., degradation will initiate. Polymer matrix should completely vanish at reasonable period to prevent any consequences due to polymer accumulation in the human body. Thus, degradation time is one of the important factors makes polymers occupied in specific bio-applications.

In this study, the new prepared IPNs are studied at three different media, FBS $(\mathrm{pH}=7.4)$, SGF $(\mathrm{pH}=1.2)$ and SIF $(\mathrm{pH}=8.2)$ depending on the weight loss measurements as a function of immersion time, as shown in Figures $8-10$. The results, in general, show that weight loss was decreased with increasing mannitol proportions in polymer matrix. This is attributed to matrix holes grown smaller with increasing crosslinking of poly(adipic anhydride-co-mannitol) and the results of ester groups are less reactive with water than acidic anhydride groups, 
which reduce solution penetration through the center of disks [21]. Also, the results show weight loss in SGF solution is significantly low compared with other media, reaching to $91 \%$ of weight loss in 126 days with N5.

Examining the results in Figure 8 reveal that there is constantly losing weight with time in SGF for PAA and IPNs. In addition, IPNs (N2-N4) are nearly closed to each other in degradation time, about $21 \%$ weight loss within 32 days and $79 \%$ within 98 days. The erosion of N5 shows clearly more resistance and good degradation behaviour. While, faster weight loss is achieved in the PAA, reaching to $93 \%$ weight loss of PAA which regularly degraded over a period of 70 days.

Figure 9 shows degradation of PAA and IPNs in PBS ( $\mathrm{pH}=7.4)$. By examining these results, the PAA weight loss is rapid raised and strongly degraded, compared to other specimens. It recorded a $90 \%$ weight loss in 37 days. Many researchers have reported that highest surface-eroding property of polyanhydride in aqueous medium among other media, SGF and SIF [21, 22], because of the strong nucleophilic attack to cleavage acidic anhydride groups of media with approximately $\mathrm{pH}=7$. Other specimens, N1-N5, were also start to degrade rapidly in the first 20 days and then, weight loss of IPNs is slight decreases. With increasing mannitol proportions in a polymer matrix, crosslinking will also increase. That means ester groups formed via crosslinking will increase instead of acidic anhydride groups and for this reason N5 appears to have less weight loss percentage over the majority of the period.

The same degradation behavior of IPNs in distilled water is shown in SIF, Figure 10. But the differences IPNs (N2-N5) are nearly closed in weight loss, and degradation of N4 is less than others during immersed period. There is also a rapid rising in degradation at the first 27 days for PAA and IPNs, just over $50 \%$ weight loss. This is attributed to high hydrolysis of ester groups in alkali media as well as cleaving of acid anhydride group [23].

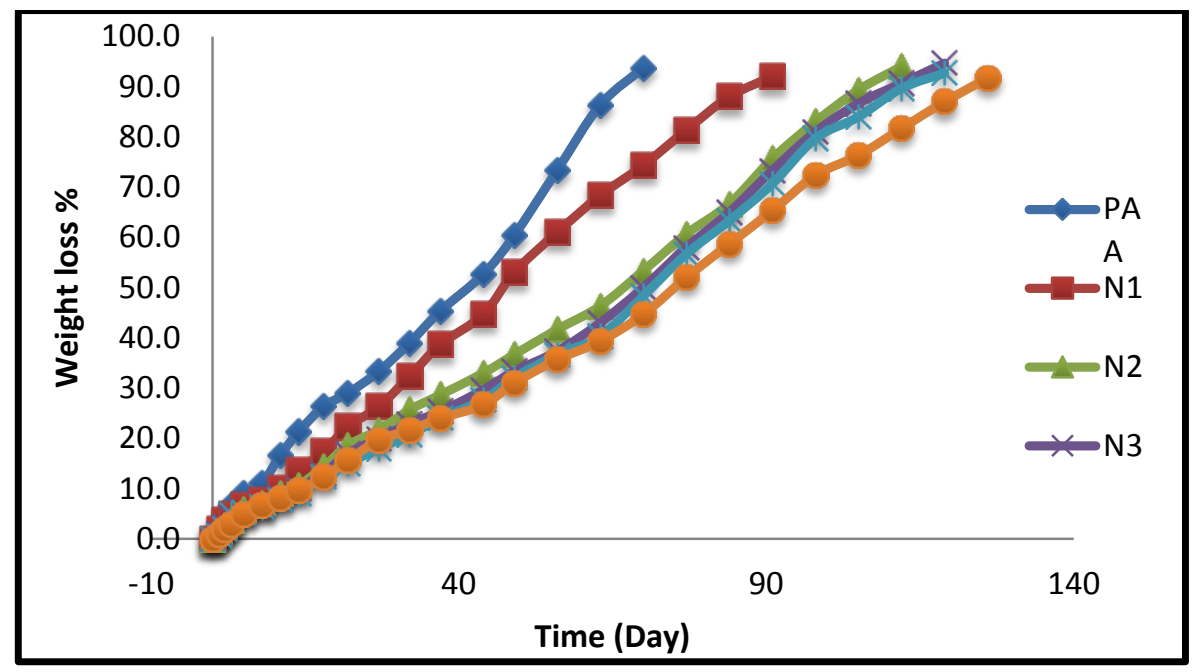

Figure 8. Weight loss percent of PAA and IPNs in SGF. 


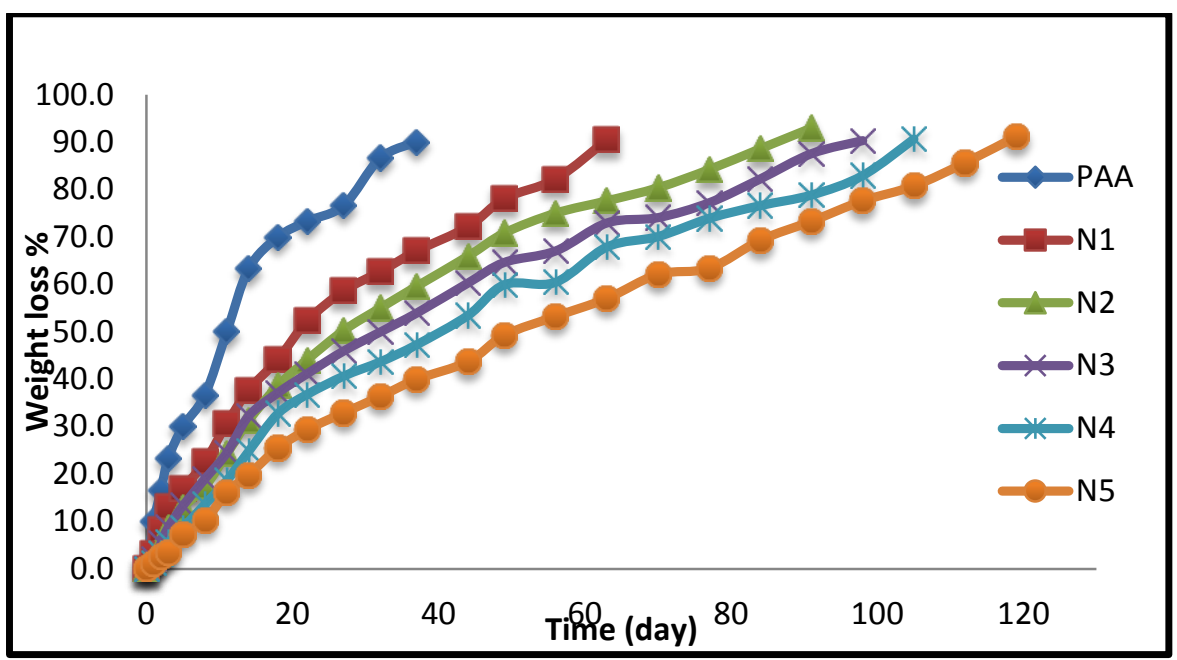

Figure 9. Weight loss percent of PAA and IPNs in PBS (pH=7.4).

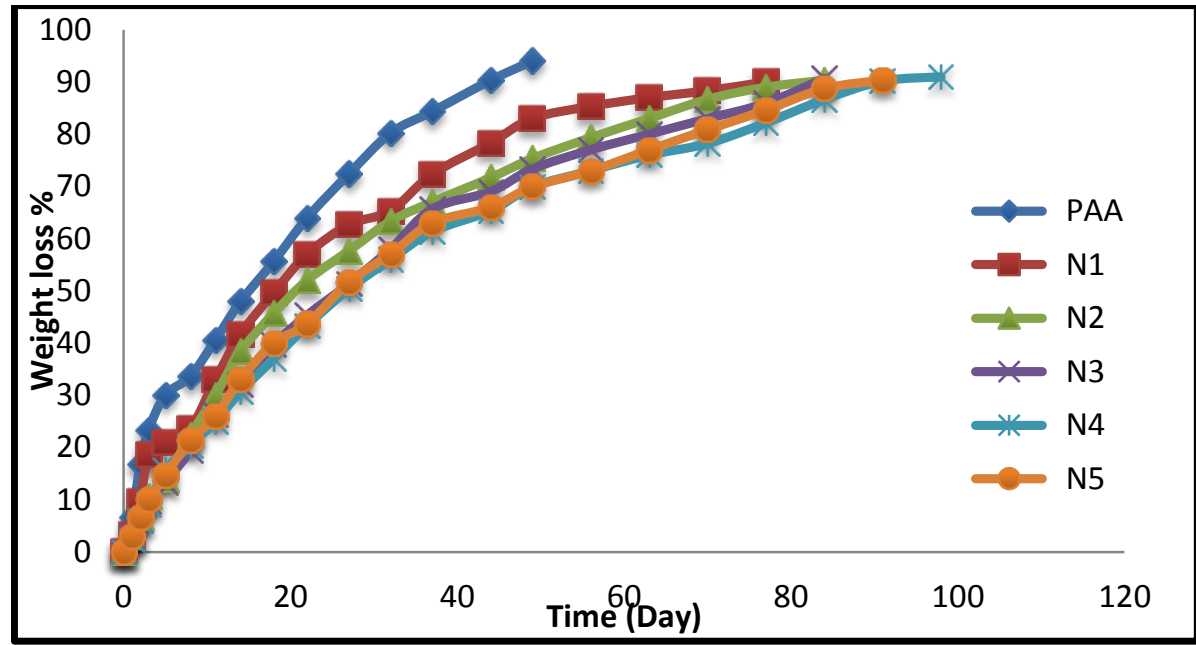

Figure 10. Weight loss percent of PAA and IPNs in SIF.

\section{Conclusion}

The polymers of poly(adipic anhydride-co-mannitol) with various molar ratios of mannitol are successfully synthesized by melt-condensation polymerization, and it is found that poly(adipic anhydride) is crosslinked by free mannitol hydroxyl groups. Also, the organic soluble chitosan, N-maleoylchitosan, is also synthesized by reaction free chitosan amino group with maleic anhydride. These are confirmed by FTIR analyses. IPNs of poly(adipic anhydride-co-mannitol)-N-maleoyl-

chitosan network was hydrolytically tested in vitro as biodegradable materials which show that biodegradation depends strongly on mannitol portion in prepared IPNs, and show much better decreasing in weight loss. More, degradability of IPNs is noticeably influenced by $\mathrm{pH}$ media and they are given less weight loss in SGF.

\section{References}

[1] Hollinger, J.O. 1995. Biomedical Application of synthetic biodegradable polymers. CRC Press, Boca Raton, FL.

[2] Uhrich, K.E., Cannizzaro, S.M., Langer, R.S. and Shakesheff, K.M. 1999. Polymeric System for control drug release. Chemical Reviews. 99(11):3181-3198.

[3] Mathiowitz, E. 1999. The encyclopedia of controlled drug delivery. John Wiley \& Sons, New York. 
[4] Park, E.S. Maniar, M. and Shah, J.C. 1998. Biodegradable polyanhydride devices of cefazolin sodium, bupivacaine, and taxol for local drug delivery: preparation, and kinetics and mechanism of in vitro release. $\mathrm{J}$. Control release. 52(1-2):179-189.

[5] Masters, D.B., Berde, C.B., Dutta, S., Turek, T. and Langer, R. 1993. Sustained local anesthetic release from bioerodible polymer matrices: a potential method for prolonged regional anesthesia. Pharmaceutical Research. 10(10):1527-1532.

[6] Sampath, P. and Brem, H. 1998. Implantable Slow-Release Chemotherapeutic Polymers for the Treatment of Malignant Brain Tumors. Journal of Cancer Control, 5(2):130-137.

[7] Carino, G.P., Jacob, J.S. and Mathiowitz, E. 2000. Nanosphere based oral insulin delivery. Journal of Control release. 65(1-2):261-269.

[8] Hui, M., Ying, F., Yan, L., Yu, L., Jianyuan, H. and Xianmo, D. 2007. Biodegradable poly(sebacic anhydride-co-caprolactone) multiblock copolymers: Synthesis, characterization, crystallinity and crystalline morphology. European Polymer Journal. 43:1055-1064.

[9] Scholz, C. and Kressler, J. 2013. Tailored Polymer Architectures for Pharmaceutical and Biomedical Applications. Sponsoring Divisions: ACS Division of Polymer Chemistry, Inc. American Chemical Society, Washington, DC 20036.

[10] Schmeltzer, R.C., Schmaleberg, K.E. and Uhrich, K.E. 2005. Synthesis and cytotoxicity of salicylate-based poly(anhydride esters). Biomacromolecules. 6(1): 59367.

[11] Vogel, B.M., Cabral, J.T., Eidelman, N., Narasimhan, B. and Mallapragda, S.K. 2005 Parallel synthesis and high throughput dissolution testing of biodegradable polyanhydride copolymers. Journal of Combinatorial Chemistry. 7(6):921-928.

[12] Brocchini, S., James, K., Tangpasuthadol, V. and Kohn, J. 1998. Structure-property correlation in a combinatorial library of degradable biomaterials. Journal of Biomedical Materials Research. 42(1):66-75.

[13] Kim, D. and Dordick, J.S. Combinatorial array-based enzymatic polyester synthesis. 2001. Biotechnology and bioengineering. 76(3):200-206.

[14] Lynn, D.M., Anderson, D.G., Putnam, D. and Langer, R. 2001. Accelerated discovery of synthetic transfection vectors: parallel synthesis and screening of a degradable polymer library. Journal of the American Chemical Society. 123(33): 2279-2285.

[15] Al-Sokanee, Z.N. 2000. Synthesis and evaluation of new drug supported polymers. M.Sc. Thesis, Chemistry department, Collثtge of Science, University of Basrah.

[16] Fan, J., Chen, J., Yang, L., Lin, H. and Cao, F. 2009. Preparation of dual-sensitive graft copolymer hydrogel based on N-maleoylchitosan and poly(Nisopropylacrylamide) by electron beam radiation. Bulletin of Materials Science. 32(5):521-526.

[17] Xu, H., Zhou, Z., Huang, K., Lei, T., Zhang, T. and Liu, Z. 2001. Preparation and properties of poly(dimer acid-sebacic acid) copolymer. Polymer Bulletin. 46:435-442.

[18] Yang, J., Webb, A.R., Pickerill, S.J., Hageman, G. and Ameer, G.A. 2006. Synthesis and evaluation of poly (diol citrate) biodegradable elastomers. Biomaterials. 27:18891898.

[19] Dong, A.J., Zhang, J.W., Jiang, K. and Deng, L.D. 2008. 
Characterization and in vitro degradation of poly(octadecanoic anhydride). Journal of materials Science: materials in medicine.19:3946.

[20] Silverstien, R.M., Webster F.X. and Kiemle, D.J. 2005. Spectrometric identification of organic compounds. $7^{\text {th }}$ Ed., John Wiley \& Sons Inc., New York.

[21] Gopferich, A. and Tessmar. J.
2002. Polyanhydride degradation and erosion. Advanced Drug Delivery Reviews. 54(7):911-931.

[22] Chen, X. and Zheng, J. 2003. Development of the biodegradable polymer-Polyanhydrides. Polymer Materials Science \& Engineering. 3:31-34.

[23] Patai, S. 1969. The chemistry of carboxylic acids and esters. John Wiley and Sons Ltd., New York.

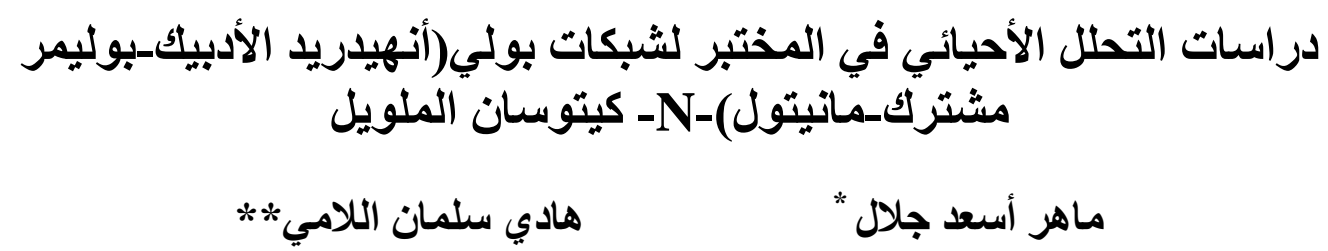

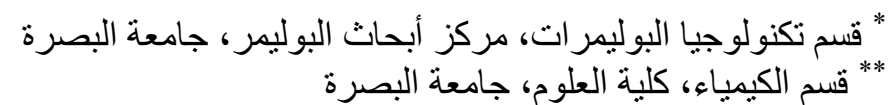

الخلاصة

في هذا العمل، تم تحضير بوليمرات جديدة من بولي(أنهيدريد الأدبيك_مانيتول) ببلمرة المنصهر ات

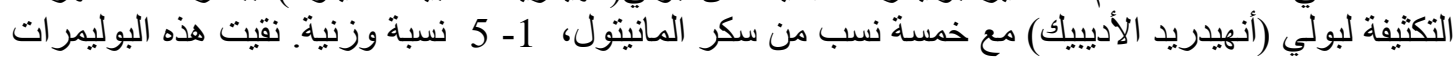

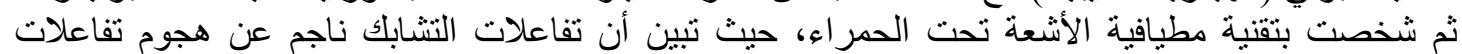

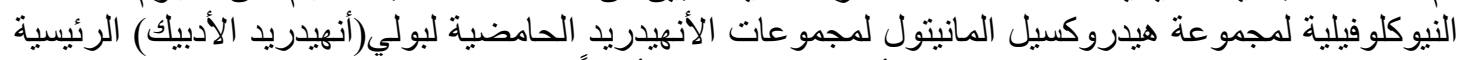

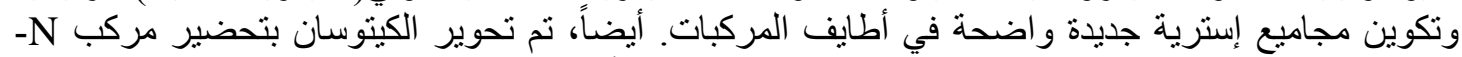

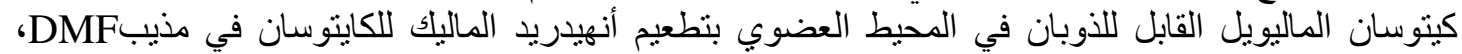

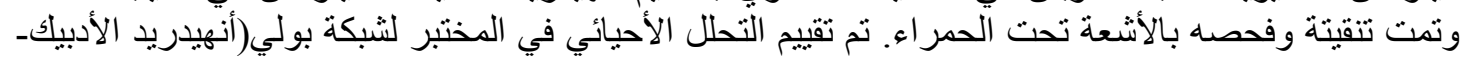

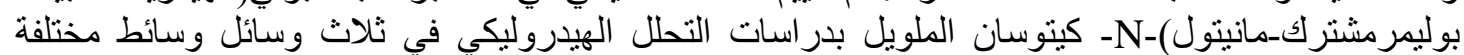
لمدة 18 أسبو عا مع 92 \% (PBS, SIF, SGF)

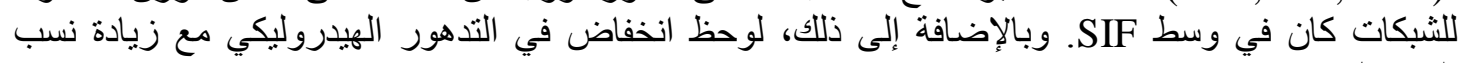
المانيتول. الكلمات المفتاحية: منصهر تكثيف، بولي(أنهيدريد الأدبيك)، مانيتول، بولي(أنهيدريد الأدبيك-بوليمرمشتركـ

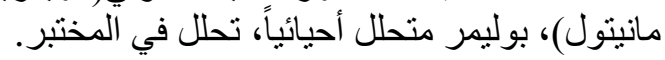

